\title{
Complete hydatidiform mole
}

INSERM

\section{Source}

INSERM. (1999). Orphanet: an online rare disease and orphan drug data base. Complete hydatidiform mole. ORPHA:254688

Complete hydatidiform mole is a type of hydatiform mole (see this term) characterized by abnormal hyperplastic trophoblasts and hydropic villi due to fertilization of an enucleated ovocyte by one or two haploid spermatozoa that can manifest with vaginal bleeding accompanied by nausea and frequent vomiting, hyperemesis gravidarum, risk of spontaneous miscarriage, hyperthyroidism, and has the potential of developing into choriocarcinoma (see this term). 